\title{
A Pastiche of Outcomes for a Teacher-Student Pair: Experiences within a Reading Cluster Group
}

\author{
Angie L. Miller ${ }^{1}$, Amanda O. Latz ${ }^{2}$, Sarah C. W. Jenkins ${ }^{2}$, Cheryll M. Adams ${ }^{2}$ \\ ${ }^{1}$ Center for Postsecondary Research, Indiana University, Bloomington, USA \\ ${ }^{2}$ Teachers College, Ball State University, Muncie, USA \\ Email: anglmill@indiana.edu, aolatz@bsu.edu
}

Received October 29 th $^{\text {th }}$ 2011; revised November 28 ${ }^{\text {th }}$, 2011; accepted December $8^{\text {th }}, 2011$

\begin{abstract}
The purpose of this study was to understand the lived experiences of two individuals involved in Project CLUE (Clustering Learners Unlocks Equity), a university-school collaboration. One former third grade teacher (T) and one of her former students (S) participated in this study. A phenomenological case study design was used. $T$ and $S$ were interviewed using a semi-structured interview protocol. The research question that drove the present study was: What are the impacts of a gifted reading curriculum on students within a gifted cluster inside a regular classroom? Three salient themes from an analysis of the interview transcripts emerged. They were: 1) social and affective outcomes; 2) bidirectional motivation for deep learning and exploration; and 3) obstacles to implementation.
\end{abstract}

Keywords: Cluster Grouping; Reading Motivation; Gifted Education; Classroom Management

\section{Introduction}

The purpose of the present study was to understand the lived experiences of two individuals involved in a Priority One Jacob K. Javits grant, Project CLUE (Clustering Learners Unlocks Equity), a university-school collaboration between a mid-western university's center for gifted studies and a large urban school corporation. Project CLUE took place between the fall of 2002 and the fall of 2007. Project goals were five-fold: 1) increase participation in gifted programs by underserved populations; 2) create a model of gifted education for underserved gifted populations; 3) provide teachers with a knowledge base to build challenging curricula for all students and gifted students in particular; 4) create opportunities for heightened parental involvement through programming; and 5) disseminate results of the project to various publics vis-à-vis publications and presentations. Part of the implementation included replacement math and reading curriculum units and cluster grouping within regular classrooms as well as professional development for teachers. Participating third, fourth, and fifth grade classes were randomly assigned to four treatments: no cluster, no curriculum; no cluster, curriculum; cluster, no curriculum; cluster, curriculum (Pierce et al., 2007).

One former third grade teacher $(\mathrm{T})$ and one of her former students (S) participated in this study. T's classroom used cluster grouping and the language arts curriculum. The math curriculum was taught by another teacher who co-taught the class with T. S was a student in the gifted cluster. A phenomenological case study design was used (Mendaglio, 2003; Moon, 1991; Patton, 2002). T and S were interviewed using a semistructured interview protocol (Spradley, 1979). S was in T's third grade class during the 2004 to 2005 school year. Interviews took place during the spring of 2009. The research question that drove the present study was: What are the impacts of a gifted reading curriculum on students within a gifted cluster inside a regular classroom? Three salient themes emerged from an analysis of the interview transcripts. They were: 1) social and affective outcomes; 2) bidirectional motivation for deep learning and exploration; and 3) obstacles to implementation. These findings will be explicated in subsequent sections.

\section{Literature Review}

\section{Cluster Grouping}

In an era of educational accountability and high stakes testing at the $\mathrm{K}-12$ level, meeting the needs of students who are gifted and talented has been trumped by meeting the needs of students struggling to meet certain academic standards. Maintaining quality educational opportunities for gifted students has also been challenged by the current dire economic situation and resultant budget cuts ("Smart Kids," 2009). As such, elementary level services for the gifted and talented have been largely relegated to general education teachers. Elementary classrooms are populated by incredibly diverse heterogeneous student groups in terms of cognitive ability, cultural background, and readiness. In these contexts, teachers often struggle to meet the needs of all students (Tomlinson et al., 1997). As such, many teachers attempt to cast their pedagogical and content nets wide by teaching to the middle with the hope of catching as many students as possible. However, in this scenario two groups of students are not caught: those at both ends of the spectrum. Cluster grouping and differentiated instruction are educational approaches meant to account for the differences found in the great majority of elementary school classrooms. By using these two inextricably linked approaches, all students can be caught in the net.

Feldhusen and Moon (1992) noted:

People who have worked in schools... would find it difficult to envision heterogeneous varsity basketball, football, and baseball teams, or a heterogeneous band comprised of beginning, intermediate, and advanced musicians. Or heterogeneous cal- 
culus for all who wish to enroll. Grouping students with similar achievement and talent levels seems to be essential if we wish to help students achieve at levels commensurate with their abilities and sustain to increase motivation to learn (p. 63).

Cluster grouping involves placing a group of gifted students in the regular elementary classroom with a teacher who possesses the requisite desire and pedagogical skills to meet the cluster students' needs (McInerney, 1983; Rogers, 2001). A critical component of cluster grouping is differentiated instruction. Kulik and Kulik (1992) stated: "It would be inefficient for a teacher to divide a class into thirds on the basis of ability and then to make the same presentation separately to each of the three groups” (p. 73). Moreover, grouping procedures must be flexible. Grouping ought to vary based on subject. For example, a student might be placed in an advanced group for reading and social studies and in an intermediate group for math. This way, students are met with the appropriate challenge in all areas. Opportunities for reassessing appropriate grouping for students should take place periodically.

Cluster grouping has many benefits. Gifted students make more academic gains through this strategy versus being a member of a heterogeneous classroom with no grouping (Kulik \& Kulik, 1992; Rogers, 1993). Furthermore, Gentry and Owen (1999) noted that total school cluster grouping "may have a positive impact on all students in a school” (p. 238). In addition to accounting for students' varying academic needs, cluster grouping may also meet schools' financial needs. Dexter (1998) said that cluster grouping was "cost effective. When funds are not available to support a self-contained classroom, this [cluster grouping] is a logical way to address these [gifted] students' needs” (p. 14). Cluster grouping allows gifted students to spend time with both their same age peers and intellectual equals (Delcourt \& Evans, 1994). In the absence of gifted students, other students in the less advanced clusters begin to emerge as achievers (Gentry \& Owen, 1999; Winebrenner, 1992).

Some researchers have suggested that cluster grouping may have negative impacts on students (e.g., Oakes, 1985). Because of the potential negative social stigma that can accompany being categorized as gifted, labeling and grouping students as such "could result in victimization" (Blanksby, 1999: p. 86). Additionally, grouping gifted students together can result in a decrease in academic self-concept (Marsh, Hau, \& Craven, 2004). This is known as the big-fish-little-pond effect. Preckel and Brüll (2008) found that girls in cluster groups suffer from greater decreases in academic self-concept. However, Rogers (1993) noted that "it is likely that there are many personal, environmental, family, and other extraneous variables which affect self-esteem and socialization more directly then the practice of grouping itself” (p. 11). It is important to consider that the benefits of cluster grouping may outweigh the negatives.

\section{Reading Motivation}

In addition to the impacts of high-stakes testing and budgetary restrictions on services for gifted students, pedagogical approaches to and intended outcomes of reading instruction have also been impacted. Williams, Herick, and Tuschinski (2008) stated that "motivating children to read on their own has been less of a priority than improving reading achievement in recent years” (p. 135). Ironically, Anderson, Wilson, and Fielding's (1988) research indicated "that time spent reading books was the best predictor of a child's growth as a reader from the second to the fifth grade” (p. 297).

Teachers can have an influence on how much time students spend reading books outside of school (Anderson et al., 1988). Extrinsic rewards for reading (e.g., prizes based on number of books read) can increase student reading. However, this approach "may not be sustainable” (Williams et al., 2008, p. 135), and it may lessen intrinsic motivation (Jensen, 1998). Wigfield and Guthrie (1997), in a study of fourth and fifth grade students, found that while reading motivation is multifaceted, intrinsic motivation is a "crucial predictor of long-term participation" (p. 429) in various activities such as reading. As such, teachers ought to develop activities, environments, and pedagogical strategies to foster intrinsic reading motivation within their students.

Several academicians have offered suggestions to assist teachers in increasing students' intrinsic motivation to read. Williams et al. (2008) suggested the following: 1) choice and control; 2) social interaction; and 3) interest. Gambrell (1996) offered several suggestions for teachers interested in motivating students to read: 1 ) the teacher as an explicit reading model; 2) a book-rich classroom environment; 3) opportunities for choice, 4) opportunities to interact socially with others; 5) opportunities to become familiar with books and; 6) appropriate readingrelated incentives. About her sixth suggestion, Gambrell wrote cautiously. She conceded that "we need to know more about the role of incentives in promoting literacy development, particularly with respect to the development of intrinsic motivation” (p. 22). Hidi and Harackiewicz (2000) stated "that the early triggering stages of situational interest may precede the development of intrinsic motivation" (p. 158). It is possible that situational interest could be catalyzed through an appropriate incentive (Guthrie, Hoa, Wigfield, Tonks, \& Perecevich, 2006). This possibility reiterates the stance that reading motivation is complex and multifarious.

Intrinsic reading motivation may decline throughout the course of a child's elementary school progress; therefore, "motivational interventions are important to establish as early as possible” (Gottfried, 1990: p. 537). Teachers' motivational interventions may take the form of the suggestions offered in the preceding paragraph. For those elementary students identified as being gifted in the area of reading, cluster grouping and accompanied differentiated instruction may serve as one of many attempts teachers can make to stabilize and increase these students' intrinsic motivation to read. Cluster grouping and differentiation inherently address student choice, collaboration, and interest. Combine these elements with a teacher who loves and models reading, heightened student access to a wide variety of reading materials, and appropriate reading incentives, and the intrinsic motivation of students with gifts and talents in reading should likely sustain or increase during the elementary years.

\section{Method \\ Project CLUE's Reading Curriculum}

A focus on critical thinking through meaningful content and challenging activities was the theoretical underpinning of the reading replacement units developed by Dr. Felicia Dixon and used with the gifted clusters in Project CLUE. Clusters contained anywhere from 3 to 8 students, with total class size in the 25 to 30 range. Students engaged in discussion, group processes, 
and writing tasks requiring consistent higher level thinking. Content for the third grade units came from three novels: Charlotte's Web (White, 1952), In the Year of the Boar and Jackie Robinson (Lord, 1984), and The Sign of the Beaver (Speare, 1983). Students read the novels, discussed and composed papers on salient themes, wrote reflective journals, built vocabulary, and used graphic organizers to express their critical thinking processes. Tasks were conducted individually and in small and large groups.

\section{Theoretical Framework and Design}

A phenomenological case study design was implemented to ascertain the lived experiences of $\mathrm{T}$ and S during the 2004-2005 academic year. Phenomenological inquiry attempts to understand "how human beings make sense of experience and transform experience into consciousness, both individually and as shared meaning" (Patton, 2002: p. 104). The present study sought to understand the various ways in which $\mathrm{T}$ and $\mathrm{S}$ experienced the third grade gifted cluster group and their use of the Project CLUE language arts replacement curriculum. Through the in-depth semi-structured interviews (Spradley, 1979) and corresponding analysis of each, the invariant structures, or essences, of the pair's experiences were identified.

Case studies research has become a preeminent methodology within the field of gifted education (e.g., Coleman, 2001; Hebert \& Beardsley, 2001). Moon (1991) noted: “Case study methods have been a cornerstone of research on giftedness" (p. 157). Mendaglio (2003) added: "By enabling us [researchers] to understand gifted persons' experiences, qualitative case study research serves to deepen our understanding of giftedness” (p. 163).

\section{Participants}

During the spring of 2007, the Project CLUE manager emailed all involved teachers to ask for names of students who thrived as a result of the curriculum. Fourteen students were nominated. During the spring of 2009, contact information for seven students was obtained from the school corporation. The remaining students could not be located. Letters and child/ guardian consent forms were mailed to invite participation in the study. Two consent forms were returned, and interviews were conducted. The researchers subsequently solicited corresponding teacher participation via email. One teacher agreed to participate, and an interview took place. This report includes the findings from the student/teacher pair. The other student interview (without corresponding teacher interview) was not considered for this paper. $\mathrm{T}$, a Caucasian female, is no longer teaching in the school corporation but is now teaching at a local community college. It is important to note here that $\mathrm{T}$ was involved in the study as both a participating teacher and as a mentor for other Project CLUE teachers. She was asked to serve as a mentor because, prior to the study, she had obtained a gifted and talented license. S, a Caucasian male, was a seventh grade student in the school corporation during the time of the interview.

\section{Analysis}

Transcriptions of the interviews were created shortly after the interviews took place. Two members of the research team were present for each interview, which took place at the participants' homes. When interviewing children, Parkinson (2001) recommends doing so in a comfortable and familiar place for the child to elicit trustworthy data. The interviewers felt this was a helpful strategy for both participants. T and S were interviewed separately. S was interviewed first. Each of the three first authors created open (Miles \& Huberman, 1994) and thematic codes for both of the transcripts independently. No a priori codes had been established. Relevant themes were identified by each researcher. Then, after a process of negotiation and dialogue, three main findings were agreed upon based on the presence of congruent themes identified by each researcher separately. This reflexive debriefing process bolstered the study’s trustworthiness (Lincoln \& Guba, 1985).

\section{Findings}

\section{Social and Affective Outcomes}

Throughout the interviews, both $\mathrm{T}$ and $\mathrm{S}$ made several references to what they believed to be positive outcomes of the cluster format and the gifted curriculum. Some of the student interview questions directly addressed self-perceived affective outcomes. In response to the question, "How did your involvement [in the cluster] make you feel about yourself?" S noted that "it felt good to know that you could do things that other people couldn't" and then further elaborated that "when you're done with the course and the school year, you achieved something that you couldn't do before or gained, uh, self-esteem or confidence in yourself, to push yourself to do more things.” $\mathrm{T}$ remarked that this sense of achievement was beneficial for not only the student, but the teacher as well, citing that if "they're having fun and they feel special, you're going to get more out of them.” This particular gifted reading curriculum appeared to challenge the student, and therefore provided him with a sense of pride in his accomplishments once he successfully read the higher-level books and completed the assignments.

In addition to the individual affective outcomes of the cluster participation, there also appeared to be positive social outcomes from the implementation of this curriculum. $S$ indicated that he enjoyed being grouped in the cluster with other students on his "level of intelligence" and that he became good friends with these students. T confirmed this statement when she recalled that "that group was a close group" and that "they would be excited just to be together." This group served as a source of social support for each other, as S reported that "you knew who could help you when you needed help.” Furthermore, students in the cluster had opportunities to provide social support to other students in the classroom, as T remembered that S "would be somebody to help another student to act as a... peer tutor or just a buddy out on the playground to help cheer somebody up.” Rather than feel alienated from the students not participating in the cluster, $\mathrm{S}$ acquired positive social experiences with both cluster and non-cluster students.

The bonds between the students in the cluster are also apparent in their self-directed interactions. The students in the cluster not only read the assigned books that were part of the curriculum, but S reported that they all chose to read the Chronicles of Narnia (Lewis, 1954/1998) on their own time and then discussed it with one another. $\mathrm{S}$ recalled this, noting that "we all read it together. It wasn't, we weren't told to do it, I remember we just read that book." The students completed this reading without the teacher's direction, as $\mathrm{T}$ was surprised when this was mentioned during her interview. "That just 
touches my heart that they would want to take their group beyond because they did love [it]," was her response to this information. While it may not be unique for gifted students to read books on their own, outside of school requirements, an important impact of the clustering format in this instance was the voluntary coordination and discussion that took place for these particular students. The cluster setup was beneficial for the students not only in learning the curriculum itself, but the positive social outcomes seem to have had an impact on their behaviors and interactions outside of the classroom setting as well.

\section{Bidirectional Motivation for Deep Learning and Exploration}

The extracurricular reading of the Chronicles of Narnia (Lewis, 1954/1998) reflects not only the positive social outcomes of the cluster format, but is also indicative of how the students' motivation was impacted through the curriculum. The students' positive responses to the books that were included in the gifted curriculum units increased their motivation to read more difficult literature, and they also took advantage of the cluster grouping format to discuss the outside reading. The students' intrinsic motivation to engage in reading for the sake of reading, rather than because it was a school assignment, resulted in a greater interest in and appreciation for literature overall. S said "I started reading more books" as an outcome of his participation in the cluster, indicating that exposure to the curriculum had a positive impact on his later behavior. $\mathrm{T}$ also noted the importance of intrinsic motivation, recalling that the cluster students "wanted to be there, they wanted to be involved, they loved that engagement." The motivation expressed by the students facilitated their learning experience, while what they learned from the curriculum in turn motivated them to further devote themselves to their interests in reading.

It should be noted that $\mathrm{T}$ expressed a high level of intrinsic motivation for teaching the cluster students as well. When referring to one particular book that was part of the gifted cluster curriculum, T stated "I just loved that book, especially when the teacher loves it, that makes it even better." She elaborated by emphasizing "I didn't have any problem executing the literature. I looked as forward to it... as the kids did.” Furthermore, T discussed the educational value she saw in the curriculum, noting that it "just had much more depth to it" and that there was "more creativity able to come out of it." S confirmed this idea about motivation, indicating that one of the most important things he learned was that "if you put your mind to it," it's possible to "read books at a higher level." Both the students and the teacher expressed motivation to fully engage in the curriculum, and to go beyond it, which then allowed for higher levels of learning to occur in the cluster setting.

Not only did T present positive social modeling for the students through her motivation to teach the curriculum, but she also reported that $\mathrm{S}$ experienced positive social modeling in his home environment as well. She noted that "the parents really stressed education and supported that, they were very visible in the school setting." S's father assisted in T's classroom as a room parent, and T elaborated on her observations of the family dynamics and values. T mentioned that she also had S's older sister as a student, and $\mathrm{T}$ stated that "both of the children in that family just spent a lot of time with their parents and a lot of, you know, modeling of good behavior and respect for other people.” This statement suggests that positive social modeling from multiple sources can have an important, even if seemingly indirect, influence on student motivation.

\section{Obstacles to Implementation}

While there were positive affective and social outcomes along with increased motivation as a result of the cluster curriculum, there appeared to be some difficult aspects as well, from the perspective of the teacher. During her interview, she reported that stringent classroom management skills were necessary for proper implementation of the gifted curriculum, especially in a classroom setting without a teacher's aide or other adult assistance. T reported:

You have to have a pretty good grip on your classroom if you're going to implement a program like this. Otherwise, this sort of thing is just a thorn in your side because you're trying to... do it all and you're trying to manage at the same time.

"The management piece is the most difficult", she noted, in trying to assure that the gifted students were getting direct instruction when it was necessary. Teaching effectively with a cluster format depends on the teacher's ability to keep students engaged and on task to ensure that students are not being disruptive or disrespectful when he or she is working with individual clusters.

Although classroom management was difficult, the subsequent benefits of executing an appropriate management system were further discussed by $\mathrm{T}$. She elaborated on some of her techniques, explaining that she incorporated "tribes" and had a "community circle.” This was a way to stress "inclusion," as T commented on the importance of:

Accepting other students for their differences and so forth. And you know you have to do that when you have special [education] children, you have to set the right tone and create this climate in a classroom so that everybody feels like they're a part, they're a contributing member... You have to set these boundaries for what's acceptable and you have to create a safe place for your students.

$\mathrm{T}$ expressed a proactive approach to classroom management. Rather than wait for problem behavior to arise before addressing disciplinary reactions, she cited the necessity of creating a supportive learning environment for all of her students, not only the students in the cluster. While this approach was initially somewhat labor- and time-intensive, it eventually allowed for easier control of the classroom when teaching different sets of curriculum to different groups of students throughout the year. While $\mathrm{S}$ was not directly questioned about classroom management issues, he did substantiate T's proactive approach. When asked how the students that were not a part of the gifted cluster reacted to the different books and lessons, he replied "I don't think they minded much," which suggests that the other students accepted the differences in ability level for the various clusters.

The teacher also reported that a lack of time was an obstacle to the proper implementation of the curriculum. She cited increased administrative demands, such as aligning lesson plans with state standards, which redirected effort away from teaching. When asked about time and classroom management, in comparing a cluster format to a self-contained classroom format, $\mathrm{T}$ speculated that the amount of time necessary for the cluster format might become problematic when using the curriculum with multiple subject areas. "I think that if you took it beyond 
two subjects, I don't know how a teacher could do that especially at [school] when you're also given special education children,” she indicated. While there were many advantages of the cluster format, there were some practical considerations voiced by the teacher as well.

\section{Discussion}

This study explored the experiences of a teacher-student pair with a gifted curriculum using a case study approach. In-depth interviews with both a student and a teacher offered a unique perspective on the impact and efficacy of a gifted reading curriculum in a cluster format. The findings of this study offer support for the use of the cluster format in an upper-elementary setting. This aligns with the results of previous research, which suggest that there are both academic (Dexter, 1998; Rogers, 2001) and social (Reed \& Westberg, 2003; Teno, 2000) benefits of clustering with gifted students. Unlike previous research (Blanksby, 1999), S did not report any negative aspects of being in the cluster, like labeling or the big-fish-little-pond effect. In fact, grouping or clustering is one approach to aid in the social and emotional development of those who are gifted (Cross, 2005). While social and emotional development is necessary for all children and adolescents, researchers postulate that giftedness adds to the stress of development (Coleman \& Cross, 2001). Research suggests those who are gifted are more likely to feel socially isolated and dissatisfied with social support (Vialle, Heaven, \& Ciarrochi, 2007). As such, clustering may be used to curb feelings of isolation and stress experienced by those who are gifted (Cross, 2005). Moreover, as was found in this study, clustering may lead to additional positive affective outcomes.

Clustering is one way to facilitate social interaction between students in the classroom. As noted earlier, several researchers have proposed that social interaction helps to foster intrinsic motivation (Gambrell, 1996; Williams et al., 2008); the results of this study support that proposal. For example, $\mathrm{S}$ was able to reflect on the benefit of working and bonding with like-minded students who were at his "level of intelligence." One might argue that while students who are gifted may inherently have a greater level of motivation to learn, allowing them to interact socially with other students who are gifted may increase intrinsic motivation, as well as aid in social and emotional development.

The third theme found in the interviews, obstacles to implementation, has also been addressed in some of the previous research on the use of clustering. The importance of providing teachers with adequate preparation time is often stressed (Teno, 2000), and there is available literature concerning some practical suggestions for implementation of cluster grouping (Gentry \& Keilty, 2004; Gentry \& Mann, 2008). It is central to recognize that while the cluster format may have many benefits for students, there are also costs in terms of teacher time and need for increased classroom management skills. However, even at a school where teacher time and resources are limited, such as the one in this case study, the cluster format can still be an effective means of providing an advanced curriculum to gifted students.

\section{Limitations}

One limitation of this study is the time lag between the curriculum and cluster implementation and the interviews. It would have been ideal to have less time between the imple- mentation of the curriculum in the cluster and the interviews, but this was not feasible. The time lag may have also contributed to the low response rate. As noted in the methods section, the researchers wanted this study to be a multiple case study, but had difficulty locating and securing participants. Furthermore, the ability to collect other evidence in addition to the interviews, such as student writing journals, critiques, or reflections, could have strengthened the conclusions concerning the value of cluster grouping.

Consideration should be given to the classroom setup when evaluating the efficacy of the findings. Winebrenner and Brulles (2008) recommended that when using a schoolwide model for cluster grouping, gifted students should not be placed in a classroom with the lowest achieving students. Similarly, the gifted student cluster should not be placed in the same class as the high achieving cluster(s). This way, the spectrum of achievement levels inside one single classroom is limited (Coleman, 1995). As noted in the findings section, T reported having both students who are gifted and those with special needs, making the spectrum of achievement very broad. This could have made clustering less effective for the gifted students.

\section{Conclusion}

The findings of this study provide evidence of the social, affective, and motivational benefits of using cluster grouping with students who are gifted. Social development may be fostered by providing a sense of belongingness and social support from other students who are gifted. This development was noteworthy to both $\mathrm{T}$ and S. S expressed a great deal of confidence, self-esteem, and pride in his ability to be challenged and complete the tasks the curriculum required. While $\mathrm{S}$ reported an increase in social and emotional well-being, he also reported a greater level of intrinsic motivation for reading books beyond the requirements of the curriculum. It is unclear if this motivation is due to the bidirectional motivation provided by the teacher and parents, the social interaction of the clusters, or the curriculum itself. What is clear is that $\mathrm{S}$ reported great benefits from the experience, as did $\mathrm{T}$. Overall, the cluster setup was effective for learning the curriculum and for social and emotional development, as well as helping the student establish higher levels of intrinsic motivation.

\section{Future Directions}

The findings from this study suggest there are benefits to using differentiated curriculum within clusters for gifted students. This research calls for more work to be done using larger-scale qualitative approaches. These could include in-class observations, or a longitudinal case study on one particular gifted cluster kept together over the course of a few years. For this type of design, perhaps focus groups would be optimal. Moreover, using a quantitative approach would help quantify the results and potentially corroborate the qualitative findings.

\section{REFERENCES}

Anderson, R. C., Wilson, P. T., \& Fielding, L. G. (1988). Growth in reading and how children spend their time outside of school. Reading Research Quarterly, 23, 285-303. doi:10.1598/RRQ.23.3.2

Blanksby, D. C. (1999). Not quite eureka: Perceptions of a trial of cluster grouping as a model for addressing the diverse range of student abilities at a junior secondary school. Educational Studies, 25, 
79-88. doi:10.1080/03055699997972

Coleman, L. J. (2001). A "rag quilt”: Social relationships among students in a special high school. Gifted Child Quarterly, 45, 164-173. doi:10.1177/001698620104500302

Coleman, L. J., \& Cross, T. L. (2001). Being gifted in school: An introduction to development, guidance, and teaching. Waco, TX: Prufrock Press.

Coleman, M. R. (1995). The importance of cluster grouping. Gifted Child Today, 18, 38-40.

Cross, T. L. (2005). The social and emotional lives of gifted kids. Waco, TX: Prufrock Press.

Delcourt, M. A. B., \& Evans, K. (1994). Qualitative extension of the learning outcomes study. Storrs, CT: The National Research Center on the Gifted and Talented.

Dexter, D. K. (1998). Cluster grouping: A strategy for effective teaching. Gifted Child Today, 21, 14-20, 48.

Feldhusen, J. F., \& Moon, S. M. (1992). Grouping gifted students: Issues and concerns. Gifted Child Quarterly, 36, 63-67. doi:10.1177/001698629203600202

Gambrell, L. B. (1996). Creating classroom cultures that foster reading motivation. The Reading Teacher, 50, 14-25.

Gentry, M., \& Keilty, B. (2004). Rural and suburban cluster grouping: Reflections on staff development as a component of program success. Roeper Review, 26, 147-155. doi:10.1080/02783190409554260

Gentry, M., \& Mann, R. L. (2008). Total school cluster grouping \& differentiation: A comprehensive, research-based plan for raising student achievement \& improving teacher practices. Mansfield Center, CT: Creative Learning Press.

Gentry, M., \& Owen, S. V. (1999). An investigation of the effects of total school flexible cluster grouping on identification, achievement, and classroom practices. Gifted Child Quarterly, 43, 224-242. doi:10.1177/001698629904300402

Gottfried, A. E. (1990). Academic intrinsic motivation in young elementary school children. Journal of Educational Psychology, 82, 525-538. doi:10.1037/0022-0663.82.3.525

Guthrie, J. T., Hoa, L. W., Wigfield, A., Tonks, S. M., \& Perecevich, K. C. (2006). From spark to fire: Can situational reading interest lead to long-term reading motivation? Reading Research and Instruction, 45, 91-117. doi:10.1080/19388070609558444

Hebert, T. P., \& Beardsley, T. M. (2001). Jermaine: A critical case study of a gifted black child living in rural poverty. Gifted Child Quarterly, 45, 85-102. doi:10.1177/001698620104500203

Hidi, S., \& Harackiewicz, J. M. (2000). Motivating the academically unmotivated: A critical issue for the 21st century. Review of Educational Research, 70, 151-179.

Jensen, E. (1998). Teaching with the brain in mind. Alexandria, VA: Association for Supervision and Curriculum Development.

Kulik, J. A., \& Kulik, C. C. (1992). Meta-analytic findings on grouping programs. Gifted Child Quarterly, 36, 73-77. doi:10.1177/001698629203600204

Lewis, C. S. (1954/1998). The chronicles of Narnia. New York: HarperCollins.

Lincoln, Y. S., \& Guba, E. G. (1985). Naturalistic inquiry. Beverly Hills, CA: Thousand Oaks.

Lord, B. B. (1984). In the year of the boar and Jackie Robinson. New York: HarperCollins.

Marsh, H. W., Hau, K., \& Craven, R. (2004). The big-fish-little-pond effect stands up to scrutiny. American Psychologist, 59, 269-271. doi:10.1037/0003-066X.59.4.269

McInerney, C. F. (1983). Cluster grouping for the gifted, the bottom line: Research-based classroom strategies. St. Paul, MN: LINE Inc.

Mendaglio, S. (2003). Qualitative case study in gifted education. Jour- nal for the Education of the Gifted, 26, 163-183.

Miles, M. B., \& Huberman, A. M. (1994). Qualitative data analysis (2nd ed.). Thousand Oaks, CA: Sage.

Moon, S. M. (1991). Case study research in gifted education. In N Buchanan \& J. Feldhusen (Eds.), Conducting research and evaluation in gifted education (pp. 157-178). New York: Teachers College Press.

Oakes, J. (1985). Keeping track: How schools structure inequality. New Haven, CT: Yale University Press.

Patton, M. Q. (2002). Qualitative research and evaluation methods (3rd ed.). Thousand Oaks, CA: Sage.

Parkinson, D. D. (2001). Securing trustworthy data from an interview situation with young children: Six integrated interview strategies. Child Study Journal, 31, 137-156.

Pierce, R. L., Adams, C. M., Speirs Neumeister, K. L., Cassady, J. C. Dixon, F. A., \& Cross, T. L. (2007). Development of an identification procedure for a large urban school corporation: Identifying culturally diverse and academically gifted elementary students. Roeper Review, 29, 113-118. doi:10.1080/02783190709554394

Preckel, F., \& Brüll, M. (2008). Grouping the gifted and talented: Are girls most likely to suffer the consequences? Journal for the Education of the Gifted, 32, 54-85.

Reed, S. E., \& Westberg, K. L. (2003). Implementing enrichment clusters in a multiage school: Perspectives from a principal and consultant. Gifted Child Today, 26, 26-29.

Rogers, K. B. (1993). Grouping the gifted and talented: Questions and answers. Roeper Review, 16, 8-12. doi:10.1080/02783199309553526

Rogers, K. B. (2001). Re-forming gifted education: Matching the program to the child. Scottsdale, AZ: Great Potential Press, Inc.

Speare, E. G. (1983). The sign of the beaver. New York: HarperCollins.

Spradley, J. P. (1979). The ethnographic interview. Chicago: Holt, Rinehart, and Winston.

Teno, K. M. (2000). Cluster grouping elementary gifted students in the regular classroom: A teacher's perspective. Gifted Child Today, 23, 44-53.

Tomlinson, C. A., Callahan, C. M., Tomchin, D. M., Eiss, N., Imbeau, M., \& Landrum, M. (1997). Becoming architects of communities of learning: Addressing academic diversity in contemporary classrooms. Exceptional Children, 63, 269-282.

USA Today. (2009). Smart kids ignored? Disparities in gifted education reported. URL (last checked 23 November 2009). http://www.usatoday.com/news/education/2009-11-23-gifted-educati on_N.htm

Vialle, W., Heaven, P. C. L., \& Ciarrochi, J. (2007). On being gifted, but sad and misunderstood: Social, emotional, and academic outcomes of gifted students in the Wollongong Youth Study. Educational Research and Evaluation, 13, 569-586. doi:10.1080/13803610701786046

White, E. B. (1952). Charlotte's web. New York: HarperCollins.

Wigfield, A., \& Guthrie, J. T. (1997). Relations of children's motivation for reading to the amount and breadth of their reading. Journal of Educational Psychology, 89, 420-432. doi:10.1037/0022-0663.89.3.420

Williams, L. M., Hedrick, W. B., \& Tuschinski, L. (2008). Motivation: Going beyond testing to a lifetime of reading. Childhood Education, $84,135-141$

Winebrenner, S. (1992). Teaching gifted kids in the regular classroom. Minneapolis, MN: Free Spirit Publishing.

Winebrenner, S., \& Brulles, D. (2008). The cluster grouping handbook: How to challenge gifted students and improve achievement for all. Minneapolis, MN: Free Spirit Publishing. 